\title{
¿FESTEJANDO CON LOS SEÑORES MOCHICAS? HACIA UNA REVALUACIÓN DE LOS FESTINES Y COMIDAS RITUALES PREHISPÁNICOS EN LOS ANDES CENTRALES
}

\author{
Nicolas Goepfert y Walter Alva
}

\begin{abstract}
Los festines fueron una práctica común y recurrente en los Andes Centrales durante la época prehispánica. Sin embargo, no existe un consenso sobre los criterios utilizados en la caracterización arqueológica de estos eventos. En este artículo revaluamos las evidencias del Repositorio de Ofrendas 1 de Sipán, un sitio Mochica (siglos tres y cuatro dC) ubicado en el valle de Lambayeque, a través del empleo de una variable cuantitativa llamada "peso de carne disponible". Asociado a la tumba del Señor de Sipán, este depósito contiene centenas de ofrendas de prestigio, pero también miles de restos de fauna. El análisis de estos últimos proporciona nuevas perspectivas sobre la comida funeraria dada en homenaje a este alto dignatario después de su entierro. El uso de la variable mencionada permite evaluar la magnitud de esta comida y muestra la importancia de definir criterios metodológicos fiables para seguir investigando los festines, eventos que constituyen una de las bases de las relaciones sociales y políticas de las sociedades prehispánicas.
\end{abstract}

The feast was a common and recurring practice in the Central Andes during Prehispanic times. Nevertheless, there is no consensus on the criteria used in the archaeological characterization of these events. In this paper, we reassess the evidence of Sipan's Offering, a Mochica site (third-fourth centuries AD) in the Lambayeque valley, testing a quantitative variable called the "available meat weight". Associated with the tomb of the Lord of Sipán, the deposit contains hundreds of prestige offerings and thousands of faunal remains. Analysis of the latter could help us assess the magnitude of the funeral meal by calculating the "available meat weight". This provides new perspectives on the funeral meal given to honor this particular high dignitary after his burial. Considering that feasts constitute one of the foundations of social and political relations in Prehispanic Andean societies, we make a case for defining reliable methodological criteria in future scholarly work on Andean feasts.

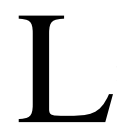

a celebración, el desarrollo y el significado de banquetes y festines han sido objeto de una abundante literatura antropológica (e.g., Blitz 1993; Dietler 1996; Dietler y Hayden 2001; Hayden 1996, 2009; Potter 2000). Estos trabajos han sido utilizados frecuentemente para identificar e interpretar numerosos contextos arqueológicos específicos. En los Andes Centrales, los términos "festín" y "banquete" han sido ampliamente empleados para caracterizar prácticas comensales. Sin poner en duda las interpretaciones de los investigadores, aquí deseamos evaluar más precisamente las variables utilizadas para la identificación arqueológica de dichos festines.
En Perú, los contextos arqueológicos de festines fueron identificados principalmente en sitios del Horizonte Temprano (e.g., Chicoine 2011; Ikehara y Shibata 2008; Ikehara et al. 2013; Kaulicke y Dillehay 2008; Vega-Centeno 2008), pero también de épocas más tardías (e.g., Bray 2003a, 2003b; Goldstein 2003; Jennings y Bowser 2009; Lau 2002, 2007; Swenson 2008). En estos trabajos, los investigadores usan diversos criterios de identificación: la tipomorfología de los recipientes de cerámica (Bray 2003b; Goldstein 2003; Ikehara \& Shibata 2008), la presencia de almidones y fitolitos de maíz (Ikehara et al. 2013), las remodelaciones de las estructuras arquitectónicas (Swenson 2008), la

\footnotetext{
Nicolas Goepfert — CNRS-Paris 1 UMR 8096 Archéologie des Amériques, 21 allée de l’Université, 92000 Nanterre, Nanterre, France (nicolas.goepfert@ cnrs.fr)

Walter Alva Museo Tumbas Reales de Sipán, Juan Pablo Vizcardo y Guzman 895, Lambayeque, Peru (tumbasdesipan@hotmail.com)
}

Latin American Antiquity 29(2), 2018, pp. 331-349

Copyright (C) 2018 by the Society for American Archaeology doi:10.1017/laq.2018.2 
asociación de vasijas de cerámica con restos de fauna (Chicoine 2011) y la cantidad de animales encontrados (Lau 2002, 2007). Si bien existen diferentes tipos de festines, resulta sorprendente la diversidad de criterios, en muchos casos cualitativos, utilizados para una misma categoría genérica de hallazgos.

Los festines pueden definirse como una forma de actividad ritual centrada en el consumo colectivo de alimentos y bebidas (Dietler 2011:180) que difieren de las comidas habituales que se desarrollan en la esfera doméstica. Citando numerosos ejemplos, Dietler (2011:181) muestra la antigüedad de esta práctica en el Viejo Mundo. Al abordar la cuestión de los banquetes galos, Méniel $(1992,2001)$ indica que estos ocupaban un lugar primordial en la vida social durante la Antiguiedad clásica. Era durante estas reuniones que se compartían y consumían las carnes (provenientes de un sacrificio sangriento) y las bebidas. Según este autor, estos dos elementos constituyen la "esencia de los banquetes” (Méniel 2001:63). Para la época prehispánica, notamos que son raros (o inexistentes) los contextos arqueológicos que presentan una asociación formal e indiscutible de estos dos elementos, aunque sí están reportados independientemente. Así, uno de los dos componentes principales de los festines es la comida consumida, ya sea de origen animal o vegetal. La presencia de restos botánicos es obviamente muy dependiente del estado de conservación, al cual se añade un sesgo metodológico causado por la ausencia o escasez de tamizaje y flotación sistemáticos de los sedimentos. Por el contrario, los restos de fauna aparecen como un material de primer orden para identificar y caracterizar estos eventos.

Hablar de festín no resulta ser tan sencillo, a pesar de que este tipo de evento agrupa una serie de manifestaciones cuyos límites son bastante amplios en términos de participantes (esfera doméstica, colectiva, etc.), de contextos culturales (funerario, matrimonio, guerra, etc.) o de función (religiosa, comunitaria, etc.). Así, no pretendemos discutir aquí los diferentes tipos de festín (competitivo, redistributivo, etc.), ya que no existen criterios arqueológicos claramente definidos y aceptados para cada una de estas categorías. Uno de los primeros objetivos consiste entonces en definir criterios específicos que diferencien un festín de una comida cotidiana.
El lugar y el contexto de descubrimiento (santuario, templo, palacio, plaza ceremonial) es fundamental para distinguir un evento de consumo ordinario de uno de consumo fuera de lo ordinario (Brisebarre et al. 2010; Goepfert 2010). Méniel (2001) resalta tres criterios para distinguirlos:

- la cantidad de animales consumidos, que debe claramente sobrepasar los niveles de consumo doméstico y cotidiano;

- la elección específica de un tipo de animal o de un pieza de carne;

- la recurrencia del registro, en distintos lugares, de patrones de selección similares.

El tercer criterio es por el momento difícil de corroborar por la falta de estudios comparativos para un mismo periodo y una misma región; los dos primeros criterios son más accesibles y pueden aplicarse a otros vestigios (como la cerámica), pero no parecen ser suficientes. Por lo tanto, agregamos dos variables adicionales:

- la cronología, que debe corresponder a un evento de duración limitada o una sucesión de eventos bien definidos cronológica y estratigráficamente;

- el espacio en el que se desarrolla este evento (esfera doméstica, pública, reservada), que podría contribuir a distinguir entre diferentes tipos de comidas.

En su artículo sobre los festines funerarios, Hayden (2009) reporta el ejemplo del túmulo de Gayhurst (Edad de Bronce) donde se encontraron los restos de al menos 300 bóvidos. Asimismo, se pueden mencionar los espectaculares hallazgos de Kerma en Sudán (Chaix 1989) donde hasta 5.000 bucráneos de reses fueron depositados alrededor de las tumbas, mientras que el resto del cuerpo de los animales fue consumido durante eventos festivos en la ciudad. En Ouessant (Francia), un sitio de la primera Edad del Hierro, se registraron 21.000 restos provenientes de al menos 460 ovejas, 70 reses, 30 cerdos, aves marinas y peces (Méniel 2001:65-67). En Chevrières (Francia), el descubrimiento de los restos de al menos seis reses y tres cerdos proporcionó una estimación de más de $700 \mathrm{~kg}$ de carne (Méniel 2001:67-68). Por otro lado, en Tell Brak (Siria), un sitio del Calcolítico tardío, se señaló 
el descubrimiento de restos de fauna depositados encima de sepulturas colectivas (McMahon et al. 2011). Por las características zooarqueológicas (fragmentación, desarticulación, huellas de corte, extracción de médula) y la cantidad de animales ( 25 bóvidos y 100 corderos), este contexto fue interpretado como un evento suntuario, es decir un festín sellando un nivel de tumbas.

Como se puede constatar, el consumo de cantidades considerables de carne marca eventos de gran magnitud que fácilmente sobrepasan una comida doméstica habitual. Por diversas razones, los estudios previos de festines en los Andes no resaltan ninguno de estos criterios, dificultando la identificación de estos eventos y su diferenciación de una comida ordinaria. La razón principal es la ausencia de estudios zooarqueológicos completos, o la realización de estudios limitados a determinaciones taxonómicas, contabilización del Número de Restos y cálculos simples del Número Mínimo de Individuos.

Las evidencias que exponemos aquí permiten proponer reflexiones comparativas sobre la magnitud de los festines en los Andes Centrales durante la época prehispánica. La primera es considerar como festín todo tipo de evento de comensalidad que se desarrolla en el marco de rituales; de esta forma, el concepto de festín abarca una larga gama de contextos. La segunda es limitar el uso de los términos festín y banquete a determinado tipo de reuniones excepcionales. Sin embargo, esto implica utilizar ciertos criterios metodológicos para identificarlos. Esta opción conduce a una primera pregunta, intencionalmente provocadora: ¿hubo realmente festines en los Andes prehispánicos? Y si hubo, ¿cuáles son los criterios y las evidencias zooarqueológicas que permiten comprobarlo? A seguir veremos si el criterio cuantitativo es fundamental o no, y si concuerda con las cantidades descritas por varios autores para la Antigüiedad clásica en el Viejo Mundo. Debemos resaltar además que los términos banquete y festín son modernos y no corresponden a un origen clásico relacionado con antiguos conceptos greco-latinos. Sin embargo, la palabra banquete es comúnmente utilizada para referirse a las prácticas griegas (y luego romanas) de comensalidad y comidas de aparato. Dentro de estas actividades, resaltan dos componentes descritos por Dentzer (1982) para el Medio Oriente y el mundo griego entre los siglos
VII-IV antes de nuestra era: el reparto de comida, deipnon, al cual sucede el symposium donde se toma el vino.

En este trabajo planteamos que el uso de los términos festín y banquete debe ser revisado puesto que parece ser inapropiado o mal empleado en muchos casos. De este modo, tal vez sería preferible hablar de comidas rituales o de ritos alimenticios de comunión en lugar de festín o banquete. Discutimos este aspecto a través de las evidencias arqueológicas y zooarqueológicas provenientes de la cultura Mochica, en particular de la plataforma funeraria de Sipán, que suele ser interpretada como el lugar de una comida funeraria con un objetivo político, jerárquico y exclusivo. Sin cuestionar la existencia de ritos colectivos con utilización de comida y bebida en el mundo andino, queremos volver a discutir el empleo indistinto de estos términos. En este trabajo nos enfocamos en un criterio metodológico empírico que no ha sido explotado por otros investigadores en los Andes para identificar estos tipos de contextos: la estimación del peso de carne disponible. A partir de esta evaluación y pensando en modelizar estas evidencias, una gran cantidad de carne correspondería a un evento colectivo que reunió a muchas personas; al contrario, una cantidad limitada de carne sería el resultado de un evento más pequeño, reservado para pocas personas. Así, la variable cuantitativa permite evaluar la amplitud de estos contextos y diferenciar las comidas rituales con un carácter reducido de posibles festines.

\section{El Repositorio 1 de Sipán: ¿Vestigios de un Festín?}

Sipán es un sitio cívico-ceremonial y funerario de la cultura Mochica ubicado en el valle de Lambayeque en la costa norte de Perú (Figura 1). Las tumbas del "Señor" y del "Viejo Señor" de Sipán son las más famosas de un conjunto de 15 descubiertas entre 1987 y 2012. Los ajuares funerarios contienen innumerables artefactos de metal y cerámica, descritos en varias ocasiones (Alva 1988, 1994, 2004; Alva y Donnan 1993), y también animales enteros: llamas (Lama glama) y alpacas (Vicugna pacos), perros (Canis familiaris), cuyes o conejillos de India (Cavia porcellus) y una serpiente (restos aún no analizados). Los mamíferos dominan 


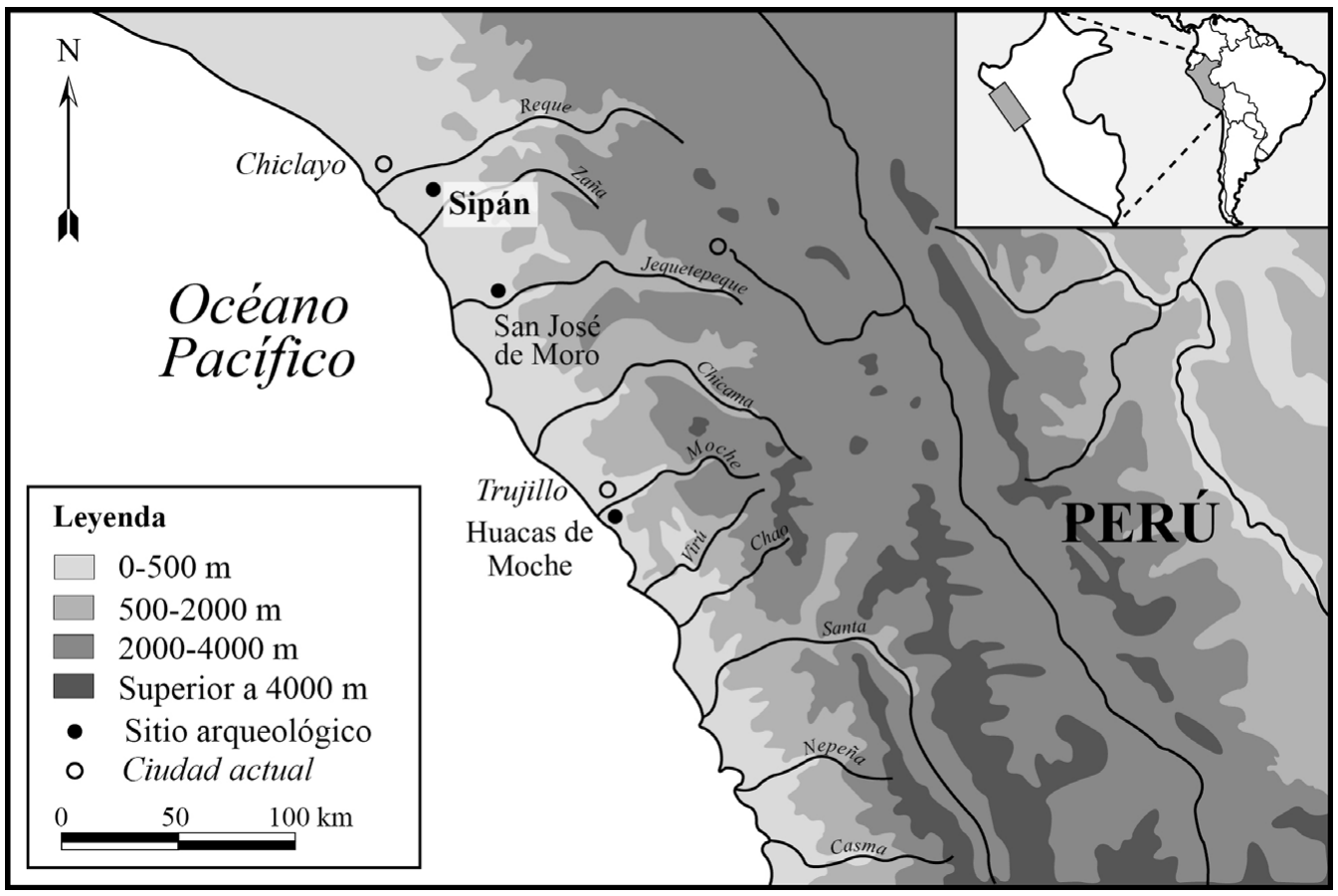

Figura 1. Localización del sitio de Sipán.

claramente el espectro faunístico y subrayan la importancia considerable de estas ofrendas en los rituales funerarios de la cultura Mochica, probablemente para acompañar y guiar al difunto hacia el inframundo (Goepfert 2011, 2012). Los restos de fauna no fueron encontrados solamente en las tumbas, sino también en cuatro grandes depósitos llamados repositorios de ofrendas que fueron receptáculos de miles de ofrendas de todo tipo (Alva 2004; Alva y Donnan 1993).

\section{La Tumba del Señor de Sipán y el Repositorio de Ofrendas 1}

La tumba del Señor de Sipán (Figura 2) es una inhumación múltiple que contiene nueve individuos enterrados en una gran cámara funeraria construida de adobe. El personaje principal es un hombre adulto, de 35 a 45 años, ubicado en el centro de la sepultura dentro de un ataúd de madera (Alva y Donnan 1993). El ajuar funerario consiste en cientos de objetos de metal (oro, plata y cobre dorado) - pectorales, tocados, tres pares de orejeras, narigueras, collares, un cetro, cuchillos ceremoniales, ornamentos múltiplesademás de cerámicas, valvas de espóndilos (Spondylus princeps) y animales (Alva 1988,
1994, 2004; Alva y Donnan 1993). Los restos de fauna se distribuyen alrededor del ataúd principal y se componen exclusivamente de mamíferos: dos camélidos (Lama sp.) y un perro (Canis familiaris).

El Repositorio de Ofrendas 1 se encuentra también en la plataforma funeraria (Figura 2) y forma parte de la misma unidad arqueológica y arquitectónica que la tumba (Alva y Donnan 1993:50-53). Mide 2,90 $\mathrm{m}$ de largo por $1,80 \mathrm{~m}$ de ancho y alcanza una profundidad de hasta $1,10 \mathrm{~m}$. En el repositorio se halló una cantidad muy impresionante de artefactos: 1.137 vasijas, cuatro coronas de cobre, una máscara de cobre, restos malacológicos como espóndilos (Spondylus princeps), objetos líticos en forma de pallares y restos óseos de animales (Figura 3; Alva y Donnan 1993:50-53; Alva 2004:32-37). ¿Cómo explicar el depósito de restos faunísticos entre otros vestigios considerados más prestigiosos? La cantidad y la calidad de los objetos muestran que este repositorio de ofrendas hecho en homenaje al difunto tenía un simbolismo particular. En ese sentido, trataremos de entender cuál podría ser el papel o la función simbólica de la fauna al interior de este contexto. 


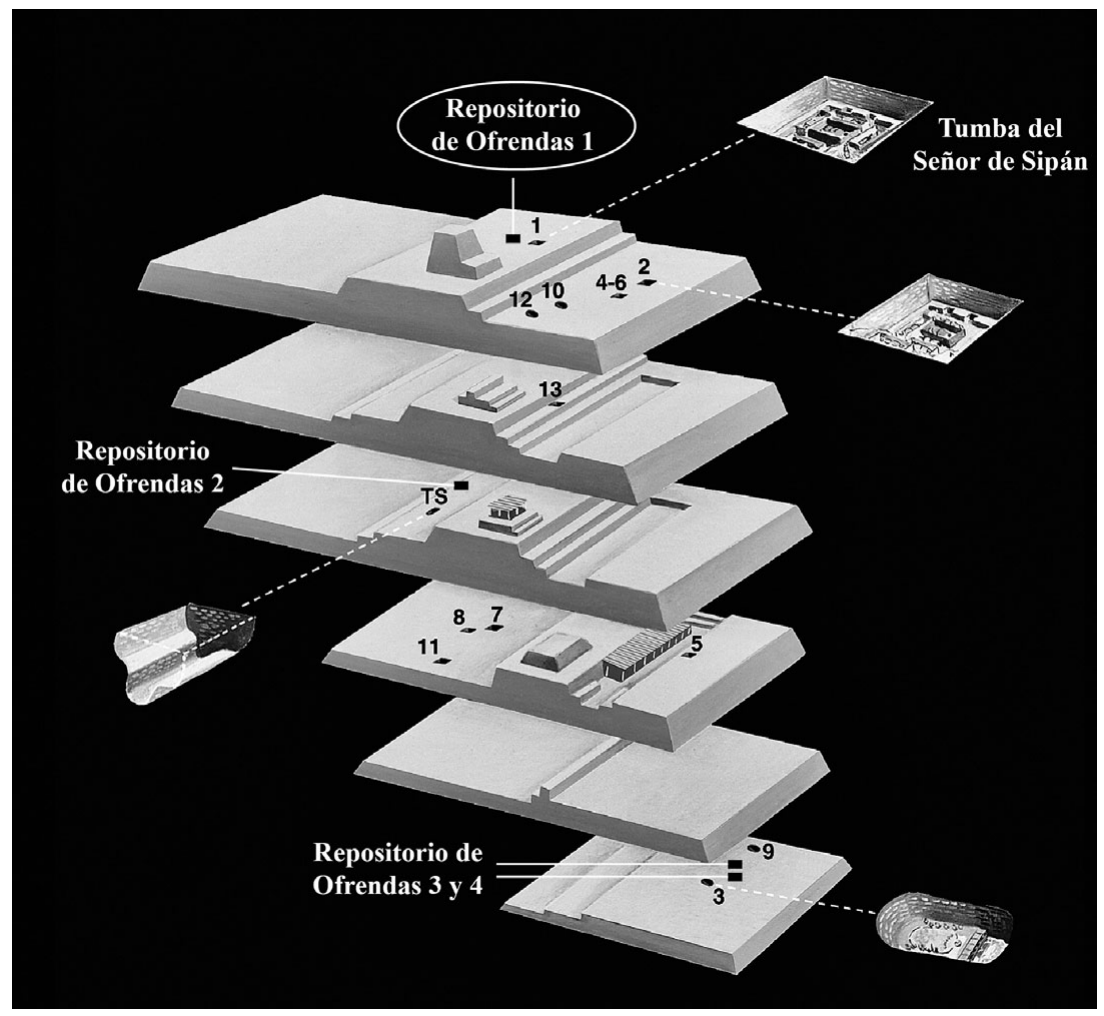

Figura 2. Reconstitución de la plataforma funeraria de Sipán con la ubicación de las tumbas y de los repositorios de ofrendas.

La tumba del Señor de Sipán y el Repositorio de Ofrendas 1 aparecen como casos singulares en razón de su tamaño, su riqueza y la complejidad del material depositado, pero también por la asociación entre un contexto funerario (la tumba) y ceremonial (el repositorio de ofrendas). A pesar de que se trata de dos contextos arqueológicos independientes, están simbólicamente ligados dentro de los funerales de este alto dignatario Mochica, lo que constituye un caso original a la escala de esta sociedad y quizás del Perú prehispánico. Estos dos contextos arqueológicos serían los vestigios de varias etapas de los funerales, es decir, el entierro y las actividades que se llevaron a cabo después de la inhumación, como parte de los rituales post-inhumación.

\section{Cuantificación e Identificación Anatómica de las Osamentas}

Durante la excavación del Repositorio 1 se registraron doce niveles arbitrarios (Alva y Donnan 1993). Los restos óseos fueron encontrados en mayor frecuencia entre los niveles seis a once, colocados por encima, por debajo y dentro de las vasijas (Figura 4) sin que su distribución mostrara algún tipo de agrupación preferencial.

Desde un punto de vista taxonómico, los restos óseos corresponden exclusivamente a camélidos domesticos (probablemente Lama sp.). Un problema importante fue la falta de cernido sistemático durante la excavación, lo que pudo ejercer un sesgo sobre la cantidad y el tamaño de los vestigios recogidos. Debido a esto, no se puede descartar totalmente la presencia de otros taxones, en particular aquellos correspondientes a microfauna (avifauna e ictiofauna).

El número de restos (NISP, por sus siglas en inglés) de camélidos analizados del Repositorio de Ofrendas 1 es de 4.436, de los cuales 1.675 (37,8\% del total) fueron determinados a nivel anatómico. La tasa relativamente alta de restos indeterminados, el $62,2 \%$ del total, se debe a la alta fragmentación que presentan los huesos. $\mathrm{Su}$ 


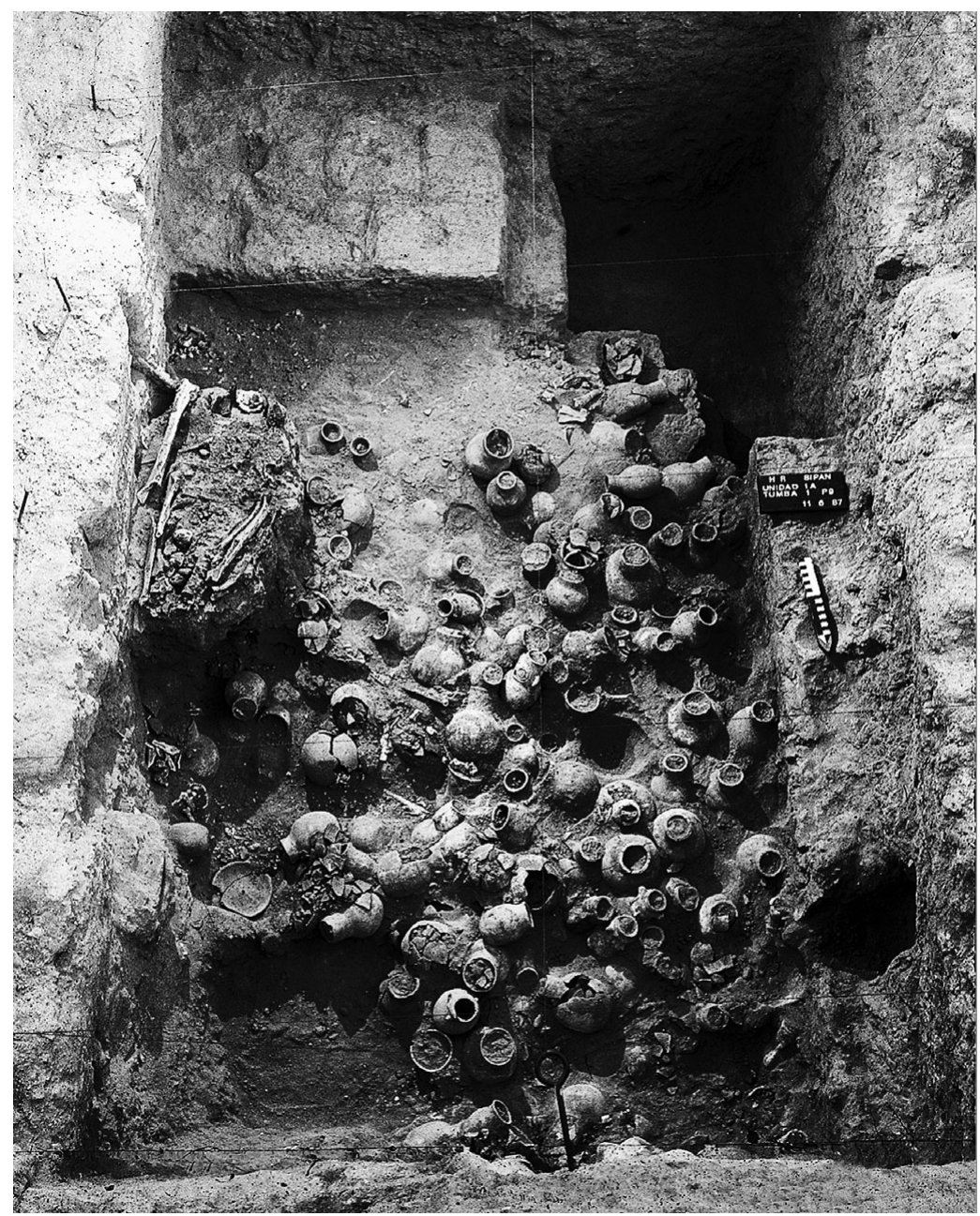

Figura 3. Vista general del Repositorio de Ofrendas 1 (fotografía de Walter Alva).

tamaño es variable: la mayoría mide menos de $1 \mathrm{~cm}$ y corresponde a fragmentos de diáfisis; otros miden entre 1 y $3 \mathrm{~cm}$ y corresponden a fragmentos de epífisis. Sin embargo, la tasa de restos indeterminados no afecta la representatividad y validez de la muestra. El número mínimo de individuos (NMI) indica la presencia de al menos 17 camélidos (Figura 5; Tabla 1). Los dos elementos más frecuentes son los cuneiformes derechos y los astrágalos izquierdos (Tabla 1). Un examen de las etapas de fusión de los huesos permite separar restos de animales jóvenes y adultos. De este modo, tomando como ejemplo el húmero, se registraron 16 derechos, de los cuales nueve corresponden a inmaduros y siete a adultos. Esta división entre animales jóvenes y adultos muestra una ligera superioridad numérica de los inmaduros y probablemente una voluntad para disponer de carne más tierna, que corresponde al modelo de estructura de edad de los camélidos descrito por Wing (1977:125).

Al observar la totalidad de las partes depositadas (Figura 5), la representación anatómica muestra que el esqueleto axial (cráneos y vértebras) está sub-representado en comparación con el esqueleto apendicular (miembros anteriores y posteriores). De manera general, las diferentes partes del esqueleto, derecha e izquierda, están representadas. Observamos, sin embargo, que los miembros anteriores y posteriores son las 


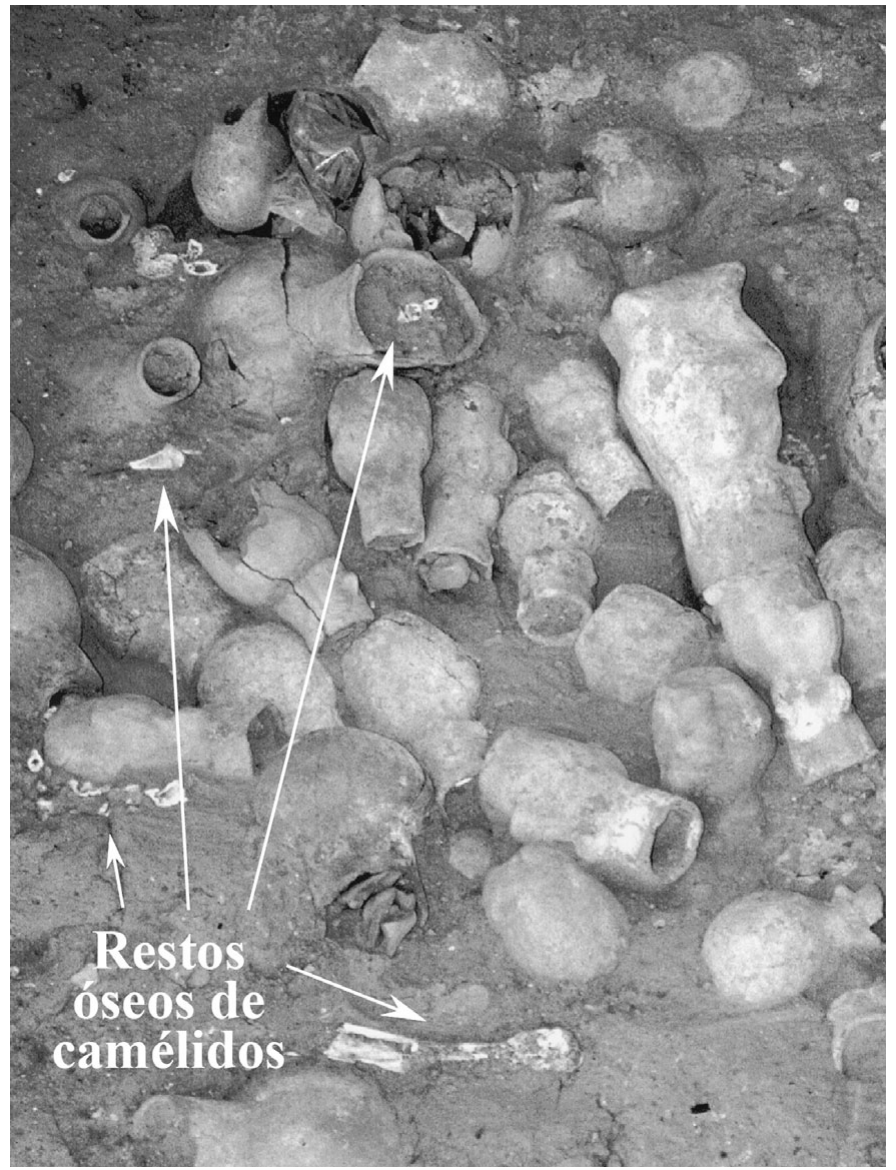

Figura 4. Restos óseos de camélidos depositados por encima, por debajo y dentro de las vasijas en el Repositorio de Ofrendas 1 (fotografía de Walter Alva).
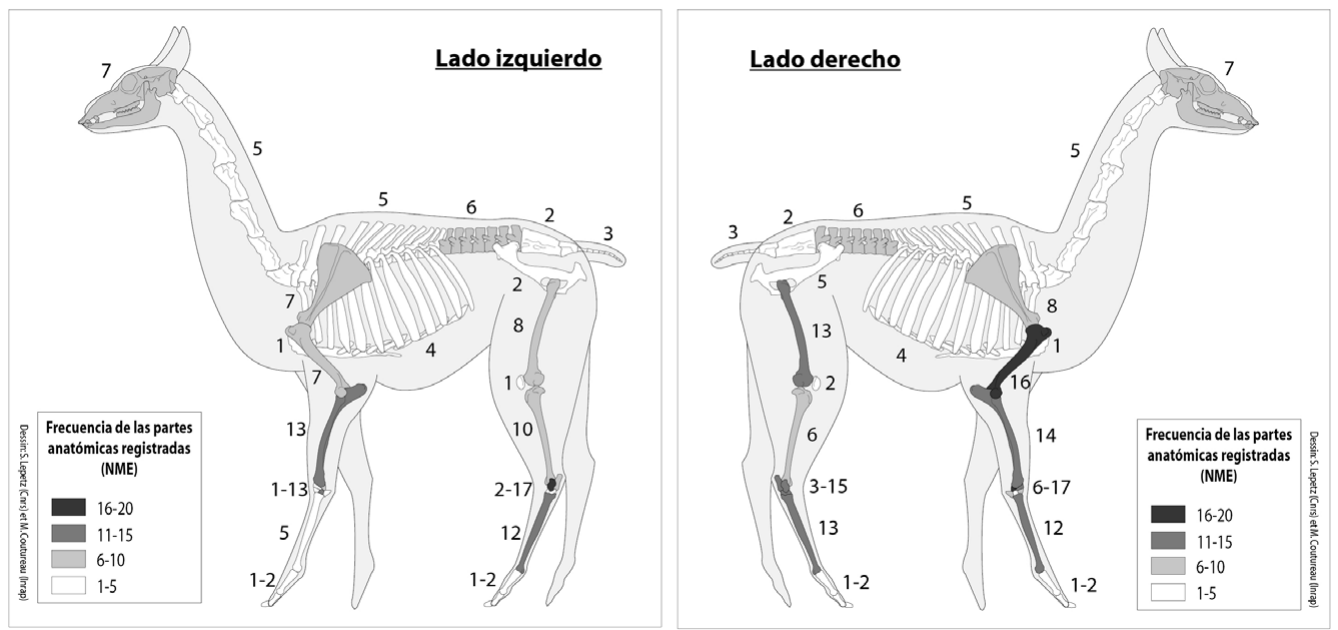

Figura 5. Frecuencia de las partes anatómicas de camélidos depositadas en el Repositorio 1 expresada en Número mínimo de porción esqueletal (NME). 
Tabla 1. Número mínimo de porción esqueletal (NME) de los Camélidos Depositados en el Repositorio de Ofrendas 1 de Sipán y Estimación del Peso de Carne Disponible.

\begin{tabular}{|c|c|c|c|c|c|c|}
\hline \multicolumn{5}{|c|}{ Parte anatómica } & \multicolumn{2}{|c|}{ Peso (en g) } \\
\hline & & & Izq. & Der. & Der. & Total \\
\hline \multirow{8}{*}{$\begin{array}{c}\text { ESQUELETO } \\
\text { AXIAL }\end{array}$} & Cabeza & $\begin{array}{l}\text { cráneo } \\
\text { mandíbula }\end{array}$ & \multicolumn{2}{|c|}{7} & 780 & 5,460 \\
\hline & \multirow{5}{*}{ Espina } & vertébra cervical & \multicolumn{2}{|c|}{5} & 1,960 & 9,800 \\
\hline & & vertébra torácica & \multirow{2}{*}{\multicolumn{2}{|c|}{$\begin{array}{l}5 \\
6\end{array}$}} & 1,680 & 8,400 \\
\hline & & vertébra lumbar & & & \multirow{2}{*}{$\begin{array}{c}1,880 \\
180\end{array}$} & 11,280 \\
\hline & & sacro & \multicolumn{2}{|c|}{2} & & 360 \\
\hline & & vertébra caudal & \multicolumn{2}{|c|}{3} & con sacro & 0 \\
\hline & \multirow{2}{*}{$\begin{array}{c}\text { Caja } \\
\text { torácica }\end{array}$} & costilla & \multirow{2}{*}{\multicolumn{2}{|c|}{$\begin{array}{l}4 \\
1\end{array}$}} & \multirow{2}{*}{$\begin{array}{l}2,040 \\
1,480\end{array}$} & 8,160 \\
\hline & & esternón & & & & 1,480 \\
\hline \multirow{33}{*}{$\begin{array}{l}\text { ESQUELETO } \\
\text { APENDICULAR }\end{array}$} & \multirow{14}{*}{$\begin{array}{l}\text { Miembros } \\
\text { anteriores }\end{array}$} & escápula & 7 & 8 & $1,450 \quad 1,320$ & 20,710 \\
\hline & & húmero & 7 & 16 & $1,440 \quad 1,510$ & 34,240 \\
\hline & & radio-ulna & 13 & 14 & $400 \quad 390$ & 10,660 \\
\hline & & lunar & 2 & 7 & \multirow{8}{*}{50} & \multirow{8}{*}{850} \\
\hline & & escafoides & 10 & 11 & & \\
\hline & & cuneiforme & 11 & 17 & & \\
\hline & & unciforme & 13 & 13 & & \\
\hline & & magnum & 4 & 9 & & \\
\hline & & trapezoide & 1 & & & \\
\hline & & pisiforme & 2 & 6 & & \\
\hline & & metacarpiano & 5 & 12 & & \\
\hline & & falange 1 & \multicolumn{2}{|c|}{2} & & \\
\hline & & falange 2 & & & 40 & 80 \\
\hline & & falange 3 & & & & \\
\hline & & pelvis & 2 & 5 & $1,200 \quad 1,120$ & 8,000 \\
\hline & & fémur & 8 & 13 & 3250 & 68250 \\
\hline & & patella & 1 & 2 & 3,250 & 68,250 \\
\hline & & tibia & 10 & 6 & 600 & 9,300 \\
\hline & & calcáneo & 11 & 15 & & \\
\hline & & astrágalo & 17 & 14 & & \\
\hline & Miembros & cuboides & 10 & 13 & & \\
\hline & Memoros & navicular & 4 & 13 & 20 & 240 \\
\hline & & entocuneiforme & 5 & 3 & 20 & 340 \\
\hline & & 1er tarso & 2 & 3 & & \\
\hline & & maléolo & 4 & 5 & & \\
\hline & & metatarsiano & 12 & 13 & & \\
\hline & & falange 1 & & & & \\
\hline & & falange 2 & & & 20 & 40 \\
\hline & & falange 3 & & & & \\
\hline & Falanoes & falange 1 & & & & \\
\hline & indranges & falange 2 & & & 30 & 60 \\
\hline & indeterminadas & falange 3 & & & & \\
\hline & NMI & & & & & 197,470 \\
\hline
\end{tabular}

partes más numerosas, en particular el húmero, radio-ulna, fémur y tibia, es decir, los elementos más ricos en carne del cuerpo del camélido (Mengoni Goñalons 2001; Olivera 2001).
Se encontraron solo 34 huellas de corte sobre los 4.436 fragmentos registrados. Estas se ubican principalmente en las costillas y, en menor medida, en las vértebras cervicales y torácicas, 


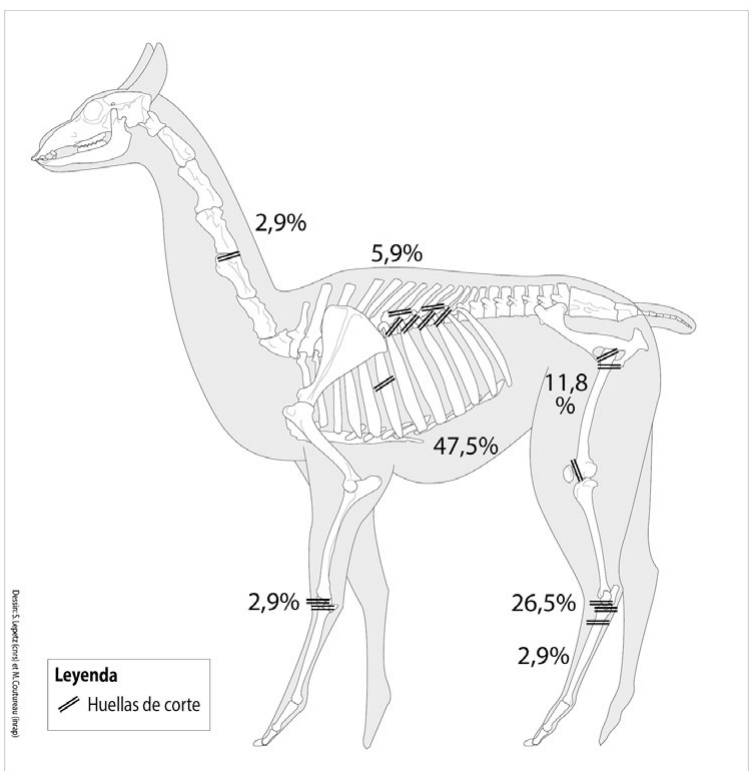

Figura 6. Ubicación y frecuencia de las huellas de corte registradas sobre los restos óseos de camélidos del Repositorio 1.

fémures, metatarsos, carpos y tarsos (Figura 6). La localización de estas huellas refleja prácticas ligadas a la desarticulación y descuartización de los animales. Dichas huellas fueron dejadas por las personas que estuvieron a cargo de la preparación de los animales o que consumieron la carne. En suma, la mayor representación de los miembros anteriores y posteriores, es decir, de las partes más sustanciosas en carne, y la elevada fragmentación de los restos óseos indican que se trata de restos de comida. Esto corresponde a un patrón clásico de consumo (Binford 1981; Wing 1972) que se distingue totalmente de los depósitos funerarios de fauna (animal entero, cráneo y extremidades o partes específicas en conexión) encontrados en las tumbas Mochicas (Goepfert 2011, 2012).

\section{Técnica de Cocción}

La celebración de una comida implica la cocción de los alimentos. En este caso, hay que señalar la ausencia de huellas de quemaduras sobre los restos óseos del depósito. Estas últimas, para ser consideradas como indicios de cocción, deben estar ubicadas en lugares específicos de los huesos (Shipman et al. 1984; Vigne y Marinval-Vigne 1983). Lepetz y Van Andringa (2008:23) señalan que la parrillada es el modo de preparación susceptible de dejar más huellas sobre los huesos, pero su proporción no excede el $2 \%$ de un corpus. Sin descartar la posibilidad de que el fuego no haya dejado ninguna huella visible, debemos considerar otros modos de cocción de la carne y de los alimentos, como el sancochado o el estofado. El uso del sancochado fue sugerido por Lau (2007) como parte de los rituales festivos que tuvieron lugar en Chinchawas en la sierra de Ancash en Perú, durante el Horizonte Medio. El estofado, también llamado pachamanca, es un modo tradicional de cocinar que tiene antecedentes en Perú desde el Precerámico (Bonavia 1982:288-289; Horkheimer 1960:137). Desde un punto de vista tafonómico, ambas técnicas de cocción evitan el contacto directo con el fuego y su uso podría explicar la falta de huellas de quemaduras en los huesos de este repositorio.

\section{Peso de Carne Disponible y Número de Participantes al Ritual}

A diferencia de las tumbas Mochicas donde los animales (o partes de ellos) se encuentran enteros y en conexión (Goepfert 2011, 2012), los restos de fauna depositados en el Repositorio 1 están muy fragmentados y corresponden a desechos de comida. Sin embargo, la multitud de objetos de 
prestigio encontrados en este contexto no permite confundirlo con un basural doméstico. Se trata de una situación inédita donde se encontraron conjuntamente artefactos que son la marca de prestigio como máscaras, coronas de cobre o miles de vasijas, y desechos de comida que normalmente se registran dentro de basurales. A pesar de esta aparente contradicción, los restos faunísticos proporcionan nuevos datos sobre los rituales que pudieron haberse realizado durante los funerales. En resumen, se registraron los restos de al menos 17 camélidos, especialmente las partes carnosas de estos animales; los huesos están muy fragmentados y presentan algunas huellas de corte, reflejando principalmente el trabajo de desarticulación de los animales para su preparación y cocción. Ahora, queda como interrogación calificar esta comida. ¿Se trató de un festín, y si fue el caso, según qué criterio? ¿Debe definirse como una comida funeraria hecha en homenaje al Señor recién enterrado? Es entonces importante profundizar la función y la magnitud de esta comida. Para esto, es necesario evaluar la cantidad de participantes y tratar de definir su identidad social.

Aunque desconocemos el peso real de los camélidos empleados para este evento, utilizamos un referencial conocido como base para el cálculo del peso de carne disponible. A partir de un trabajo experimental, Olivera (2001) calculó el rendimiento en carne de cada elemento anatómico de una llama de 2 años y 7 meses. El animal pesaba $76,5 \mathrm{~kg}$; el peso de la carcasa eviscerada fue de $41,8 \mathrm{~kg}$ y el peso de la carne disponible de $26,7 \mathrm{~kg}$. Un error en este caso sería multiplicar esta cantidad de $26,7 \mathrm{~kg}$ por los 17 camélidos (NMI) registrados en el repositorio. Recordemos que los cuerpos no fueron encontrados completos y que los elementos anatómicos no estaban presentes con la misma frecuencia (Figura 5). De esta manera, para llegar a una evaluación más precisa del peso de carne disponible, se multiplicó cada parte anatómica identificada por el peso de carne del elemento correspondiente según las cifras proporcionadas por Olivera (2001; Tabla 1). Así, obtenemos un peso de $197,5 \mathrm{~kg}$ de carne disponible.

Pasar del peso de carne al número de consumidores es una etapa hipotética que presenta riesgos inherentes a este tipo de estimación.
El objetivo de este cálculo no es acercarse al número exacto de participantes (esto sería imposible), sino proporcionar una idea de la magnitud de esta comida. En su trabajo sobre el sitio de Tell Brak, teniendo en cuenta la totalidad de la fauna depositada, McMahon y coautores (2011) estimaron a $21.300 \mathrm{~kg}$ la carne disponible. Atribuyendo una ración de $1 \mathrm{~kg}$, llegan a una cifra de 7.100 personas festejando en el sitio durante tres días. Así, en Sipán, si se atribuye la misma ración y si consideramos que la carne fue consumida al mismo tiempo, llegamos a 197 personas. Bajando la ración a $300 \mathrm{~g}$, se llega a 658 raciones $(197,5 \mathrm{~kg} / 0,3 \mathrm{~kg}=658,3)$. Sin embargo, no tenemos ninguna certeza sobre el hecho que todos los trozos de carne fueron consumidos durante un mismo y único evento. De este modo, debemos tener en cuenta una gama de posibilidades que pudieron haber tenido lugar:

- 197 personas para una comida con una ración de $1 \mathrm{~kg}$;

- 658 personas para una comida con una ración de $300 \mathrm{~g}$;

- 329 personas para dos comidas con una ración de $300 \mathrm{~g}$;

- 1.316 personas para una comida reduciendo la ración a $150 \mathrm{~g}$;

- 47 personas para dos comidas por día durante una semana con una ración de $300 \mathrm{~g}$.

Se podrían multiplicar las propuestas sin que este procedimiento sea pertinente. Una primera observación rápida muestra que la magnitud de esta comida es mucho menor que los festines descritos por McMahon y coautores (2011) o Méniel (2001). En estos contextos, la cantidad de carne disponible supera la tonelada, un peso netamente superior a la estimación hecha sobre los restos del Repositorio 1.

Debemos señalar que, a diferencia de varios contextos descritos en la literatura sobre los Andes prehispánicos, este repositorio corresponde a un solo evento, corto y limitado en el tiempo, y no es el resultado de la acumulación de varias comidas sucesivas cuya cronología es más larga y sin un control estratigráfico estricto. Si bien es cierto que se trata de un peso importante, $197 \mathrm{~kg}$ de carne disponible tampoco es una cifra exorbitante, sobre todo si consideramos 
que se trata de una comida fúnebre dada en homenaje a un personaje tan prestigioso como lo fue el Señor de Sipán. Este hecho contradice de cierta manera los registros etnográficos actuales donde los festines funerarios son considerados como los eventos más importantes, costosos y ostentatorios de la vida de una familia (Hayden 2009:29). Si se toma en cuenta el ajuar funerario o la cantidad de vasijas del repositorio, se podría esperar que la comida funeraria fuera también desmesurada en cuanto a la carne consumida. No fue el caso. Sin embargo, es importante tener en cuenta que no sólo se consume carne en este tipo de comida, sino también verduras y frutas, sin olvidar otros productos como la médula ósea y las vísceras que hacían parte del "menú".

\section{Productos Derivados, Verduras y Frutas}

Entre los restos recuperados en el Repositorio 1 no se encontraron fracturas helicoidales características de la extracción de médula, pero la alta fragmentación de los huesos sugiere esta práctica. Las vísceras son una materia orgánica que lamentablemente no deja rastros arqueológicos. Sin embargo, forman un complemento importante y se podría considerar que eran, como la médula, consumidas durante estas comidas. Podemos también pensar que la carne fue probablemente servida con verduras (maíz, papas, camotes, etc.), frutas y líquidos.

\section{Consumo de Chicha}

El consumo de bebidas alcohólicas, en particular la chicha, es un elemento fundamental de los rituales andinos pasados y actuales (Jennings y Bowser 2009; Saignes 1993). Los descubrimientos arqueológicos confirman la fabricación antigua de chicha desde al menos el Horizonte Temprano (Ikehara et al. 2013). Tinajas que servían probablemente para preparar o almacenar esta bebida fueron descubiertas en los sitios de Huacas de Moche y San José de Moro (Delibes Mateos y Barragán Villena 2008). Otros elementos de la iconografía, como una botella escultórica Mochica representando dos personas preparando chicha (Donnan 1978:66), atestiguan su fabricación durante esta época. Ikehara y Shibata (2008) discuten este aspecto con la estimación del volumen de las vasijas de servicio, vinculadas al consumo de líquidos.
La preponderancia de vasijas de servicio es un elemento frecuentemente utilizado por los investigadores para identificar eventos festivos. Una vez más, el problema mayor que encontramos es la selección de un solo criterio (dentro de varios necesarios) para identificar un festín. En este sentido, el trabajo de Lau $(2002,2007)$ se destaca por asociar datos cuantitativos sobre la fauna y vasijas de servicio.

Solo algunas vasijas del Repositorio 1 de Sipán fueron publicadas, pero Alva (2004:3435) detalla las formas depositadas. Se puede notar que la mayoría de las vasijas son cántaros con una variedad que va desde formas simples hasta formas escultóricas (personajes de la elite, prisioneros, músicos, etc.), además de algunos cuencos y una botella asa-estribo en forma de iguana. Por la repetición de las formas y el acabado burdo, Alva (2004:35) sugiere que estas vasijas fueron fabricadas únicamente para ser depositadas como ofrendas, probablemente para dar una impresión de cantidad y como homenaje al difunto. Alva resalta además que existen agrupaciones, disposiciones particulares y tal vez escenas donde se encuentran asociados dos tipos de vasija. El grupo mayoritario está constituido por vasijas de boca abierta como ollas medianas y grandes sin cuello $(n=15)$, cántaros globulares y ovoides $(n=727)$ y otros fragmentados $(n$ $=80$ ). No se encontraron platos. La pequeña capacidad de las vasijas permite descartar su uso para la elaboración de bebidas y alimentos para los cuales se prefiere usar ollas grandes y tinajas. Los cántaros tienden a ser utilizados para el servicio, principalmente de líquidos.

\section{Reparto de la Carne}

Un último punto queda por discutir. Como se mencionó anteriormente, en el Repositorio 1 no se hallaron todas las partes de los 17 camélidos representados. De hecho, no es posible asegurar que los restos óseos de este contexto correspondan a la totalidad de la carne consumida en esta ocasión. Es necesario preguntarse cómo y dónde fue utilizado el resto de los cuerpos de los animales. Se puede sugerir que las otras partes anatómicas fueron, en el marco de estos funerales, probablemente repartidas, consumidas y enterradas en otros lugares del sitio. Los participantes pudieron haber comido en otras partes 
de la plataforma, o del sitio de Sipán, en sectores que todavía no se excavan o cuyos vínculos con esta estructura no han sido establecidos. En consecuencia, la cantidad de carne consumida puede haber sido mayor y entonces el número de participantes también.

Nada impide pensar que las partes faltantes o bien fueron compartidas entre los presentes, o sirvieron de compensación por el servicio religioso, o pudieron ser utilizadas como ofrendas en las tumbas. Si hubo un reparto, solo implicó las porciones moderadamente carnosas - cráneos, vértebras, etc.- que no presentan el mismo rendimiento económico que las "paletillas" (los húmeros) o las "piernas" (los fémures) encontradas en el Repositorio. En San José de Moro, por ejemplo, Castillo Butters (2012) observa un reparto diferencial según el estatus del individuo: los de mayor rango fueron depositados con los elementos más ricos de los camélidos y los de menor estatus con las extremidades de patas de camélidos, un patrón que suele ser común dentro de las prácticas funerarias Mochicas (Goepfert 2012). En el mundo grecorromano, el reparto de la carne del sacrificio era una práctica normalizada (Lepetz y van Andringa 2008; van Andringa y Lepetz 2003). En efecto, partes del cuerpo de los animales sacrificados eran ofrecidas a los muertos, pero también al oficiante en retribución del acto ritual (Méniel 2001:7475); otras eran consumidas y, por último, algunas vendidas en los mercados. Lepetz y van Andringa (2008) hacen hincapié sobre la importancia de los aspectos rituales, también profanos, vinculados con el corte de los animales y su reparto entre muertos y vivos.

Los términos del reparto, en el caso aquí considerado, siguen siendo desconocidos, pero solo parece involucrar el esqueleto axial de los animales, sin distinción de edad (inmadurosadultos). Quedaría por verificar la existencia de una repartición por sexo, pero el dimorfismo sexual de los camélidos domésticos es aún difícil de determinar y en consecuencia queda como un tema por explorar.

Aunque controvertidas, las estimaciones realizadas previamente sobre el peso de carne disponible dan una idea de la magnitud de esta comida ritual. Dada la singularidad de este entierro y del alto estatus de la persona enterrada, la comida funeraria asociada reunió, al parecer, un número mediano o tal vez pequeño de personas. Algunos aspectos adicionales deben ser considerados, tales como la necesidad de definir quiénes fueron los destinatarios de estos alimentos y quiénes fueron autorizados a comer en la plataforma funeraria de Sipán. En una sociedad tan jerarquizada como la de los Mochicas, se puede imaginar que el acceso a esta estructura era reservado a la elite o a una categoría social específica como se resaltó en otros sitios (Uceda 2013).

\section{¿Una Comida Funeraria Reservada a la Elite?}

\section{¿Una Comida Exclusiva más que Colectiva?}

El Repositorio de Ofrendas 1 agrupa los vestigios de un rito post-inhumación que consistió en actividades religiosas o profanas en honor al Señor de Sipán. Los restos de fauna corresponden a una comida funeraria, pero queda por saber si este evento fue exclusivo (restringido a la elite) o colectivo (compartido con un grupo más grande). Los restos óseos suelen proporcionar información importante acerca de la función del contexto y de la posible composición social de los participantes. Aunque la carne no fue el único elemento consumido, consideramos que la cantidad estimada, es decir, $197 \mathrm{~kg}$, no permite apoyar la hipótesis de un festín amplio, sino más bien de una comida reservada a una pequeña parte de la población. En primer lugar, esta comida pudo tratarse únicamente de una actividad familiar, circunscrita y de carácter privado. En segundo lugar, es posible que este evento haya reunido a las autoridades religiosas, los guerreros, los otros miembros de la elite y quizás los artesanos vinculados al grupo gobernante.

Por lo tanto, hay que interrogarse sobre la naturaleza de esta comida funeraria. ¿Tuvo un carácter político y exclusivo, reflejo de la jerarquía Mochica, o un carácter colectivo, donde las diferencias sociales fueron temporalmente ignoradas? Si socialmente esta comida solo fue destinada a un número reducido de personas pertenecientes a la elite, su alcance político fue más amplio y sirvió probablemente para reafirmar el orden social y confirmar la dominación 
de los dirigentes Mochicas. En este sentido, una comida de carácter político, que reúne a las principales autoridades del sitio, parece ser una hipótesis más plausible. Además, al mismo tiempo que refuerza su autoridad sobre los grupos que están bajo su dominación, la elite gobernante se encarga de la sucesión del Señor difunto. A pesar de que ignoramos los modos de transmisión del poder en esta época, el final de los funerales debía también ser un momento de inestabilidad donde se ponían en práctica estrategias de alianza y de poder, especialmente durante estas comidas rituales. De hecho, no se pueden descartar las relaciones políticas con los otros sitios del valle de Lambayeque; tal vez hubo una delegación de otros dirigentes Mochicas presente en los funerales.

Tampoco se puede descartar totalmente la posibilidad de un festín colectivo. En tal caso, queda por preguntar si la población del sitio de Sipán habría asistido a los funerales de su Señor. Así, planteamos que la jerarquía se ejercía en una forma vertical (social) y también horizontal (espacio). La elite gobernante era probablemente la única autorizada a estar presente en la plataforma funeraria durante los ritos, a comer y beber en este lugar en honor del difunto, mientras que el resto de la población celebró la muerte de su líder fuera del perímetro reservado. En este caso, no se puede excluir que otros restos de comida se encuentren en diferentes partes del sitio. Ignoramos, por ejemplo, dónde se localiza el lugar de preparación de los animales. La ubicación de las cocinas es desconocida, a pesar de ser un punto fundamental para el conocimiento de los santuarios y la identificación de las prácticas religiosas (van Andringa y Lepetz 2003).

\section{Platos Reservados a la Elite}

Las escenas de funerales de altos dignatarios Mochicas son conocidas como el "Tema del Entierro" y están descritas por Donnan y McClelland (1979, 1999), McClelland y coautores (2007:122) y Castillo Butters (2000). En la parte baja de estas escenas se observa el ataúd o fardo del difunto rodeado de su ajuar y ofrendas. Los participantes forman una asamblea ubicada por ambos lados de un túnel de acceso a la tumba (Figura 7). Esta asamblea está compuesta por miembros de la elite Mochica, por personajes híbridos y, en ciertos casos, por animales como cérvidos y zorros (Donnan y McClelland 1999:276, Figura 6.152). Podemos identificar sacerdotes, músicos y guerreros. Estas representaciones parecen mostrar que únicamente la elite podía participar en los entierros de un alto dignatario.

Los alimentos y líquidos preparados para los rituales son considerados como agentes unificadores de estos eventos especiales. Antes del descubrimiento de este tipo de contextos arqueológicos, solo la iconografía Mochica aportaba datos sobre la composición de las comidas rituales. Se conocen vasijas reproduciendo la forma de verduras y frutas, y otras representando personas durante el proceso de selección e intercambio de alimentos (Arsenault 1993). ¿A quién estaban destinadas? La famosa escena de la "Presentación de Ofrendas" (Figura 8a; Larco Hoyle 1939:Plancha XXXL) muestra platos de alimentos presentados y ofrecidos a varios personajes de la elite Mochica. Estos platos superpuestos recuerdan vasijas escultóricas (botellas asa-estribo y cántaros) representando platos superpuestos que contienen alimentos animales - llama (Figura 8b), camarones, peces- y vegetales —maíz, maní (Figura 8c), ají-. En el lado derecho de esta escena se observan también cántaros llenos de líquido, probablemente chicha. Los cántaros Mochicas presentan frecuentemente una cuerda pintada o modelada alrededor del cuello. Se trata de un elemento estilístico que permite identificar una ofrenda o un elemento ofrecido (Arsenault 1992; Benson 1975:108; Bourget 1994:97, 129) como en el caso de un cántaro descubierto en la Huaca Cao Viejo en El Brujo (Figura 8d). Estos platos y cántaros están figurados con piernas, como si estuvieran animados. Este tipo de representaciones está reportado en varias escenas (McClelland et al. 2007:122, Figura 3.126), en particular las de línea fina, lo que podría ser una referencia a ritos alimenticios.

En esta escena de la "Presentación de Ofrendas", los alimentos y líquidos están principalmente destinados a los miembros de la elite quienes están ubicados bajo una pequeña estructura techada que representa probablemente una plataforma o pirámide. Los dignatarios son 


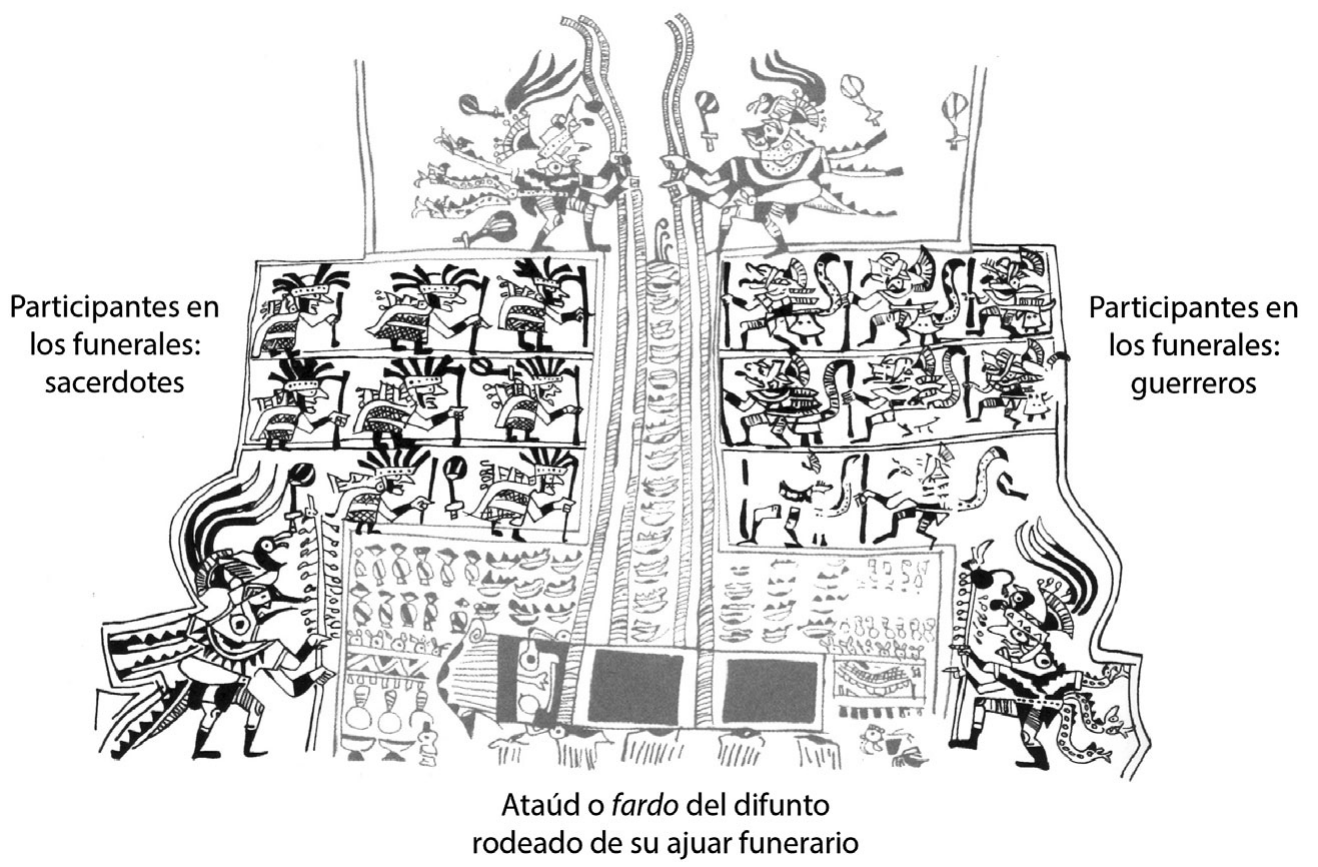

Figura 7. Detalle de la representación del "Tema del Entierro" con los participantes en los funerales (modificado de Donnan y McClelland [1999:Figura 5.46]).

A

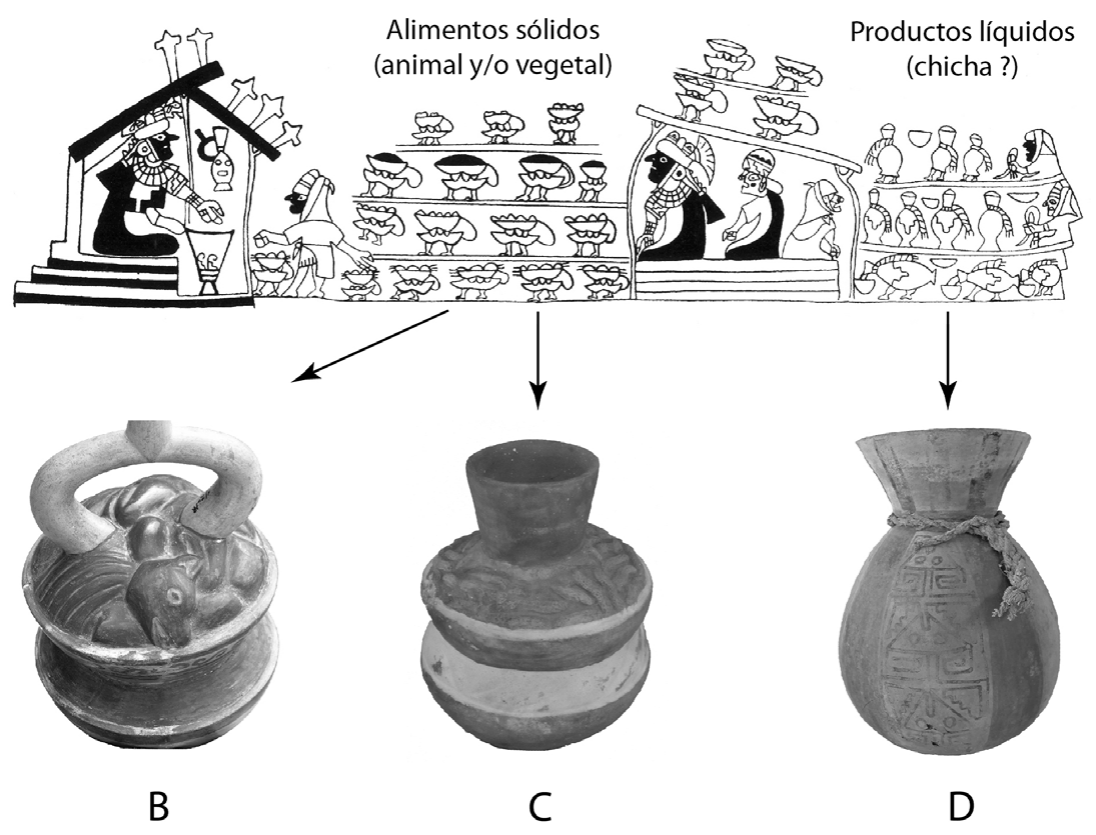

Figura 8. Representaciones de ofrendas alimenticias: (a) escena de la "Presentación de Ofrendas" (modificado de Larco Hoyle [1939:Plancha XXXL]); (b) botella asa-estribo escultórica representando platos de comida superpuestos conteniendo partes de un camélido (fotografía de Nicolas Goepfert); (c) cántaro escultórico representando platos de comida superpuestos conteniendo maní (fotografía de Nicolas Goepfert); (d) cántaro con una soga alrededor del cuello (fotografía cortesía de Segundo Vásquez). 
reconocibles gracias a sus vestidos, adornos, tocados, orejeras, pectorales y brazaletes. Al contrario, las personas encargadas de ofrecer los platos son de condición social inferior y están representados de acuerdo a cánones estilísticos opuestos, es decir, son más pequeños y sin adornos. Aunque no sabemos en qué contexto se produjo esta escena, algunos elementos como el lugar y la actitud de los personajes parecen sugerir que se trataba de un ritual, tal vez de preparación y reparto de una comida como la que tuvo lugar en la plataforma funeraria de Sipán. La abundancia de ofrendas alimentarias, representadas por la multitud de platos y cántaros, simboliza también la riqueza de la elite Mochica.

Un elemento singular es el contraste entre las múltiples representaciones de platos y vasos en la iconografía y la relativa ausencia de estas vasijas en el registro arqueológico Mochica. Como lo señala Castillo Butters (2012) para el sitio de San José de Moro, los platos y cucharas suelen aparecer con mucha más frecuencia durante las fases Transicional y Cajamarca. Esto hace suponer que los Mochicas consumieron sus alimentos en platos vegetales como los mates (Lagenaria siceraria), sumando así otra variable a considerar cuando se trata de estudiar la vajilla utilizada en eventos festivos.

\section{Discusión}

Este trabajo proporciona datos novedosos sobre la celebración en la época Mochica de comidas rituales que eran conocidas principalmente desde la iconografía (Arsenault 1992, 1993). En la plataforma funeraria de Sipán, una comida política pudo haberse celebrado al mismo tiempo que una comida colectiva, sin que podamos por el momento documentar arqueológicamente los dos eventos. La preparación de esta comida movilizó un gran número de personas, de los más religiosos - los sacerdotes y los oficiantes - a los seculares - los ganaderos y los agricultores-. La cuantificación del peso de carne disponible realizada a partir de los restos óseos encontrados en el Repositorio 1 abre nuevas perspectivas sobre el tipo de rituales, la composición social de los participantes y el alcance de las ceremonias que podían desarrollarse durante los funerales de personas impor- tantes. El ejemplo de Sipán permite también revaluar el alcance de dichos rituales y comidas, además de revisar la terminología utilizada y usar elementos cuantitativos para medir su importancia.

No existen muchos datos comparativos para la época Mochica. En San José de Moro (Figura 1), el Contexto de Ofrendas A38 proporcionó un NMI de 88 camélidos (Goepfert 2011), pero con una representación diferencial de las partes anatómicas del cuerpo, ya que los elementos depositados fueron cráneos y extremidades de miembros. En este contexto, no se trata de un festín sino de un ritual propiciatorio. El hecho interesante para nuestra reflexión no es tanto la cantidad de restos presentes sino los ausentes. En efecto, siendo partes pobres en carne, la cabeza y las extremidades de miembros no tienen un valor proteico fuerte y es entonces pertinente calcular el peso de carne de todos los elementos anatómicos ausentes que corresponden a las partes carnosas de los camélidos. De este modo, llegamos a una cifra de $1.157 \mathrm{~kg}$ de carne ausente. ¿Cuál fue el destino de esta carne? ¿Fue repartida y consumida durante un evento ritual? ¿Fue distribuida entre los vivos y llevada a los sectores domésticos? Aunque no se encontraron aún las partes anatómicas faltantes, podemos imaginar que fueron consumidas durante eventos rituales que requirieron una cantidad de carne muy importante. Sobrepasar la tonelada de carne es poco usual y este consumo podría entrar en la categoría de comidas de mayor magnitud de tipo festín. Asimismo, el contexto denominado Elemento 21, ubicado en la Plataforma Uhle en el sitio de Huacas de Moche (Figura 1), permitió registrar 6.235 restos de camélidos (NISP) y miles de restos de pescados (Chauchat y Gutiérrez 2010:187-193). Este contexto consiste en una acumulación de capas compactas, principalmente con restos óseos y fragmentos de cerámica. A la diferencia de Sipán, no se trata de un solo evento sino de una sucesión de pequeños acontecimientos. Los restos corresponden a desechos de comida cuya duración permanece desconocida (la cronología relativa es Moche I). Sin ser descritos en detalle, estos dos ejemplos muestran la diversidad de situaciones posibles para una misma cultura y permiten matizar las evidencias registradas en Sipán, al 
mismo tiempo que confirman la originalidad del Repositorio 1.

A diferencia de otros contextos clasificados como festines que se realizaron en grandes plazas ceremoniales durante mucho tiempo, el Repositorio 1 es un contexto cerrado correspondiente a un solo evento realizado en un lapso de tiempo relativamente corto. Se diferencia entonces de otros contextos donde las actividades rituales se desarrollaron a largo plazo sin un control cronológico estricto que permita delimitar el contexto. La duración de los eventos es una variable fundamental que permite ponderar la cantidad de comida consumida. Un evento de unas horas, unos días o varios eventos sucesivos que se desarrollan durante decenas de años no dejarán el mismo tipo ni la misma cantidad de vestigios; así, se puede esperar una cantidad mucho más importante de restos en eventos largos que cortos. Sería arriesgado ignorar cualquier tipo de criterio cuantitativo y solo basarse en criterios cualitativos. En nuestra opinión, las variables cuantitativas y cronológicas son fundamentales. En este sentido, el trabajo de Lau $(2002,2007)$ es uno de los más completos porque toma una variable ("usable meat weight", definida por Miller [1979]) que intenta cuantificar los vestigios encontrados. En su trabajo, además de analizar la cerámica registrada, el autor toma también en cuenta la estratigrafía, que suele ser continua y corresponde a un evento único y corto. El estado de conservación también difiere de lo encontrado en los basurales domésticos. Es la multiplicación de criterios lo que permitió a Lau medir la importancia de las actividades en Chinchawas. Si se controlan estos aspectos y se relaciona la duración de la ocupación o evento con la cantidad de restos, es posible ponderar sus datos y llegar a interpretaciones tal vez más razonables, y no identificar festines solo con el hecho de encontrar restos de comidas o vajilla de servicio en plazas o sectores ceremoniales.

Constatamos que existe un desfase metodológico entre antropólogos y arqueólogos en la identificación de un festín, ya que, para los festines antiguos, los investigadores pueden únicamente basarse sobre los vestigios encontrados. En este sentido, el Repositorio 1 de Sipán responde a varios criterios propuestos anteriormente: la cantidad de carne que suele ser más abundante que el consumo habitual; la selección de una familia de animales, los camélidos, y de partes específicas ricas en carne; el lugar, por su ubicación específica en una plataforma funeraria; y la asociación con cerámica utilitaria que, aunque no es exactamente la vajilla de servicio, cumple una función similar. Consideramos entonces que cualquier estudio especializado en un solo tipo de vestigio no es suficiente para caracterizar un festín; al contrario, es necesario considerar el conjunto de varios tipos de evidencias, dentro de los cuales el criterio cuantitativo, el contexto espacial y el control cronológico son fundamentales. Estas consideraciones nos llevan a un último aspecto que concierne al vocabulario. A pesar de la importante cantidad de carne disponible en Sipán, pensamos que no podemos hablar de festín, sino más bien de una importante comida ritual y funeraria dada en homenaje al Señor. La cantidad de carne estimada no corresponde al nivel de desmesura esperado si se compara con la magnitud de la tumba de este dignatario Mochica. El carácter excepcional está evidentemente dado por la localización del depósito, en la misma plataforma funeraria, lo cual lo diferencia de un consumo doméstico clásico y resalta su valor simbólico.

\section{Conclusión}

Servir comida durante los funerales sigue siendo hoy en día una práctica muy común en los Andes. Se encuentran ejemplos de entierros en la costa norte (Velásquez 2001) y la sierra sur del Perú o el altiplano boliviano (e.g., Carter 1968; Harris 1983; Robin 2008), donde la familia del difunto se reúne antes y después del entierro. No hemos utilizado estos datos comparativos para guiarnos únicamente con las evidencias arqueológicas disponibles y proponer a través de ellas y de este contexto nuevos elementos de reflexión.

Sugerimos revaluar la pertinencia del uso de los términos festín y banquete para ciertos hallazgos. Siguiendo la definición dada por Dietler (2011) y adaptándola a una realidad arqueológica, todos los restos de alimentos encontrados en plazas, templos, recintos o contextos ceremoniales suelen ser considerados 
como parte de un festín sin ninguna consideración cuantitativa. Por el contrario, Hayden $(1996,2009)$ subraya que los festines funerarios son más importantes y prestigiosos cuando domina la desmesura. Si este criterio prevaleciera, nos preguntamos si se podría aplicar a los Andes prehispánicos. Es únicamente el desarrollo de análisis zooarqueológicos completos que incluyan al menos el cálculo del NISP, NMI y número mínimo de porción esqueletal (NME) con la repartición anatómica de las partes depositadas, con criterios pertinentes y su asociación con otras evidencias arqueológicas (estratigrafía y cronología controlada, cerámica, restos botánicos, etc.), que permitirá afinar nuestra visión de estos eventos de comensalidad y definir con más claridad su magnitud.

El Repositorio 1 de Sipán concentra los vestigios de una comida ritual que forma parte de los funerales y no tiene equivalente en los Andes. La distribución de las partes anatómicas y la estimación del peso de carne disponible mostraron que se trata de un evento que reunió probablemente a la elite Mochica del sitio. Sin rechazar el uso de los términos "festín" y "banquete", quisimos al contrario volver a discutirlos y, asimismo, revaluar su uso para la época prehispánica.

Agradecimientos. Agradecemos a los arqueólogos y trabajadores que participaron en este formidable hallazgo en Sipán. Agradecemos también a los directores de los proyectos de los sitios arqueológicos Mochicas (C. Chauchat, L.J. Castillo) quiénes permitieron estudiar el material faunístico proveniente de contextos ceremoniales y depósitos de ofrendas. Muchas gracias a V. Chamussy, S. Vásquez, C. Lefèvre y S. Lepetz por sus múltiples comentarios sobre la metodología, las interpretaciones y lecturas preliminares de este texto, y a Paola Gomez por la revisión final del manuscrito. Agradecemos también a los evaluadores por sus comentarios que permitieron mejorar este trabajo.

Declaración de Disponibilidad de Datos. Los datos utilizados en este artículo están disponibles en informes y publicaciones. En caso que se requieran más detalles, los mismos pueden ser solicitados a través de los autores.

\section{Referencias Citadas}

\section{Alva, Walter}

1988 Discovering the New World's Richest Unlooted Tomb. National Geographic Magazine 174(4):510549.
1994 Sipán. Cervecería Backus et Johnston, Lima.

2004 Sipán. Descubrimiento e investigación. Edición del autor, Lima.

Alva, Walter y Christopher B. Donnan

1993 Royal Tombs of Sipán. Fowler Museum of Cultural History-University of California, Los Angeles.

Arsenault, Daniel

1992 Pratiques alimentaires rituelles dans la société Mochica: Le contexte du festin. Recherches amérindiennes au Québec 22:45-64.

1993 El personaje del pie amputado en la cultura mochica del Perú: Un ensayo sobre la arqueología del poder. Latin American Antiquity 4(3):225-245.

Benson, Elizabeth. P.

1975 Death-Associated Figures on Mochica Pottery. En Death and Afterlife in Pre-Columbian America, a Conference at Dumbarton Oaks (October 27th, 1973), editado por Elizabeth P. Benson, pp. 105-144. Dumbarton Oaks Research Library and Collection, Washington, DC.

Binford, Lewis R.

1981 Bones: Ancient Men and Modern Myths. Academic Press, New York.

Blitz, John H.

1993 Big Pots for Big Shots: Feasting and Storage in a Mississippian Community. American Antiquity 58(1):80-96.

Bonavia, Duccio

1982 Los Gavilanes. Precerámico peruano: Mar, desierto y oasis en la historia del hombre. Cofide, Oficina de Asuntos Culturales, Instituto Arqueológico Alemán, Comisión de Arqueología General y Comparada, Lima.

Bourget, Steve

1994 Bestiaire sacré et flore magique: Écologie rituelle de la culture Mochica, côte nord du Pérou. Tesis doctoral inédita, Department of Anthropology, Université de Montréal.

Bray, Tamara L.

2003a Inka Pottery as Culinary Equipment: Food, Feasting, and Gender in Imperial State Design. Latin American Antiquity 14:3-28.

$2003 \mathrm{~b}$ The Commensal Politics of Early States and Empires. En The Archaeology and Politics of Food and Feasting in Early States and Empires, editado por Tamara L. Bray, pp. 1-13. Kluwer Academic y Plenum Publishers, New York.

Brisebarre, Anne-Marie, Anne-Elène Delavigne y Bernadette Lizet ( editoras)

2010 Meat and Societies: Ordinary and Extraordinary Diet. Anthropozoologica 45(1).

Carter, William E.

1968 Secular Reinforcement in Aymara Death Ritual. American Anthropologist 70(2):238-263.

Castillo Butters, Luis Jaime

2000 Los rituales Mochica de la muerte. En Los dioses del antiguo Perú, editado por Krzysztof Makowski, pp. 103-135. Banco del Credito, Lima.

2012 San José de Moro y el Fin de los Mochicas en el Valle de Jequetepeque, Costa Norte del Perú. Tesis doctoral inédita, Department of Anthropology, University of California, Los Angeles.

Chaix, Louis

1989 Animaux et sépultures, deux exemples: le dolmen M XI à Sion (Suisse) et la nécropole de Kerma (Soudan). Anthropozoologica NS(3):43-51. 
Chauchat, Claude y Belkys Gutiérrez

2010 Excavaciones en la Plataforma Uhle. Temporada 2009. En Informe técnico 2009. Proyecto Arqueológico Huaca de la Luna, editado por Santiago Uceda y Ricardo Morales, pp. 184-218. Facultad de Ciencias Sociales, Universidad Nacional de la Libertad, Backus, Fondación Wilson, Trujillo, Perú.

Chicoine, David

2011 Feasting Landscapes and Political Economy at the Early Horizon Center of Huambacho, Nepeña Valley, Peru. Journal of Anthropological Archaeology 30(3):432-453.

Delibes Mateos, Rocío y Alfonso Barragán Villena

2008 El consumo ritual de chicha en San José de Moro. En Arqueología Mochica. Nuevos Enfoques. Actas del Primer Congreso Internacional de Jóvenes Investigadores de la Cultura Mochica, Lima, 4-5 de agosto de 2004, editado por Luis J. Castillo Butters, Hélène Bernier, Grégory Lockard y Julio Rucabado Yong, pp. 105-117. Institut Français d'Études Andines, Fondo Editorial de la Pontificia Universidad Católico del Perú, Lima.

Dentzer, Jean-Marie

1982 Le motif du banquet couché dans le Proche-Orient et le monde grec du $\mathrm{VII}^{e}$ au IV $\mathrm{V}^{e}$ siècle avant J.-C. École française de Rome, Paris.

Dietler, Michael

1996 Feasts and Commensal Politics in the Political Economy: Food, Power and Status in Prehistoric Europe. En Food and the Status Quest: An Interdisciplinary Perspective, editado por Polly Wiessner y Wulf Schifenhövel, pp 87-125. Berghahn Books, Oxford.

2011 Feasting and Fasting. En The Oxford Handbook on the Archaeology of Ritual and Religion, editado por Timothy Ingersoll, pp. 179-194. Oxford University Press, Oxford.

Dietler, Michael, y Brian Hayden ( editores)

2001 Feasts: Archaeological and Ethnographic Perspectives on Food, Politics, and Power. Smithsonian Institution Press, Washington DC.

Donnan, Christopher B.

1978 Moche Art of Peru: Pre-Columbian Symbolic Communication. Museum of Cultural History, University of California, Los Angeles.

Donnan, Christopher B. y Donna McClelland

1979 The Burial Theme in Moche Iconography. Studies in Pre-Columbian Art and Archaeology 21. Dumbarton Oaks, Washington, DC.

1999 Moche Fineline Painting: Its Evolution and Its Artists. Fowler Museum of Cultural History, University of California, Los Angeles.

Goepfert, Nicolas

2010 Llama and Deer: Food and Symbolical Dualism in the Central Andes Area. Anthropozoologica 45(1):2541.

2011 Frayer la route d'un monde inversé. Sacrifice et offrandes animales dans la culture Mochica (100-800 apr. J.-C.), côte nord du Pérou. B.A.R. International Series 2278. Archaeopress, Oxford.

2012 . New Zooarchaeological and Funerary Perspectives on Mochica Culture (100-800 A.D.), Peru. Journal of Field Archaeology 37(2):104-120.

Goldstein, Paul S.

2003 From Stew Eaters to Maize Drinkers: The Chicha Economy and the Tiwanaku Expansion. En The Archae- ology and Politics of Food and Feasting in Early States and Empires, editado por Tamara L. Bray, pp. 143-172. Kluwer Academic y Plenum Publishers, New York.

Harris, Olivia

1983 Los muertos y el diablo entre los Laymi de Bolivia. Chungara 11:135-152.

Hayden, Brian

1996 Feasting in Prehistoric and Traditional Societies. En Food and the Status Quest: An Interdisciplinary Perspective, editado por Polly Wiessner y Wulf Schifenhövel, pp. 127-148. Berghahn Books, Oxford.

2009 Funerals as Feasts: Why Are They So Important? Cambridge Archaeological Journal 19:29-52.

Horkheimer, Hans

1960 Alimentación y obtención de alimentos en el Perú prehispánico. Instituto Nacional de Cultura, Lima.

Ikehara, Hugo y Koichiro Shibata

2008 Festines e integración social en el Periodo Formativo : Nuevas evidencias de Cerro Blanco, valle bajo de Nepeña. En Boletín de Arqueología PUCP $n^{\circ} 9-2005$. Encuentros : Identidad, poder y manejo de espacios públicos, editado por Peter Kaulicke y Tom D. Dillehay, pp. 123-159. Pontificia Universidad Católica del Perú, Lima.

Ikehara, Hugo C., J. Fiorella Paipay y Koichiro Shibata

2013 Feasting with Zea Mays in the Middle and Late Formative North Coast of Peru. Latin American Antiquity 24:217-231.

Jennings, Justin y Brenda J. Bowser

2009 Drink, Power, and Society in the Andes. University Press of Florida, Gainesville.

Kaulicke, Peter y Tom D. Dillehay (editores)

2008 Boletín de Arqueología PUCP n9-2005. Encuentros: Identidad, poder y manejo de espacios públicos. Pontificia Universidad Católica del Perú, Lima.

Larco Hoyle, Rafael

1939 Los Mochicas. Tomo 2. Casa editora La Crónica y Variedades S.A., Lima.

Lau, George F.

2002 Feasting and Ancestor Veneration at Chinchawas, North Highlands of Ancash, Peru. Latin American Antiquity 13:279-304.

2007 Animal Resources and Recuay Culture: Transformations at Chinchawas (Ancash, Peru). Andean Past 8:449-476.

Lepetz, Sébastien y William van Andringa

2008 Archéologie du sacrifice animal en Gaule romaine. Rituels et pratiques alimentaires. Edition Monique Mergoil, Montagnac, Francia.

McClelland, Donna, Donald McClelland y Christopher B. Donnan

2007 Moche Fineline Paintings from San José de Moro. Cotsen Institute of Archaeology Press, University of California, Los Angeles.

McMahon, Augusta, Arkadiusz Sołtysiak y Jill Weber

2011 Late Chalcolithic Mass Graves at Tell Brak, Syria, and Violent Conflict During the Growth of Early City-States. Journal of Field Archaeology 36(3): 201-220.

Mengoni Goñalons, Guillermo. L.

2001 Variabilidad de la anatomía económica en la llama. En El uso de los camélidos a través el tiempo, editado por Guillermo L. Mengoni Goñalons, Daniel E. Olivera y Hugo D. Yacobaccio, pp. 145-153. Ediciones del Tridente, GZC, ICAZ, Buenos Aires. 
Méniel, Patrice

1992 Les sacrifices d'animaux chez les Gaulois. Éditions Errance, Paris.

2001 Les Gaulois et les Animaux. Élevage, repas et sacrifice. Éditions Errance, Paris.

Miller, George R.

1979 An Introduction to the Ethnoarchaeology of the Andean Camelids. Tesis doctoral inédita, Department of Anthropology, University of California, Berkeley.

Olivera, Daniel E.

2001 Perfil etario y rendimiento económico de Lama glama. En El uso de los camélidos a través el tiempo, editado por Guillermo L. Mengoni Goñalons, Daniel E. Olivera y Hugo D. Yacobaccio, pp. 179-202. Ediciones del Tridente, GZC, ICAZ, Buenos Aires.

Potter, James M.

2000 Pots, Parties, and Politics: Communal Feasting in the American Southwest. American Antiquity 65:471492.

Robin Azevedo, Valérie

2008 Miroirs de l'autre vie. Pratiques rituelles et discours sur les morts dans les Andes de Cuzco (Pérou). Société d'Ethnologie, Nanterre, Francia.

Saignes, Thierry

1993 Borrachera y memoria. La experiencia de lo sagrado en los Andes, Travaux de l'Institut Français d'Études Andines (IFEA), tomo 69. Hisbol e IFEA, Lima.

Shipman, Pat, Giraud Foster y Margaret Schoeninger

1984 Burnt Bones and Teeth: An Experimental Study of Color, Morphology, Crystal Structure and Shrinkage. Journal of Archaeological Science 11(4):307325.

Schulting, Rick

2008 Foodways and Social Ecologies: Early Mesolithic to the Early Bronze Age. En Prehistoric Britain, editado por Joshua Pollard, pp. 90-120. Blackwell, London.

Swenson, Edward R.

2008 Competitive Feasting, Religious Pluralism, and Decentralized Power in the Late Moche Period. En Andean Archaeology III: North and South, editado por William H. Isbell y Helaine Silverman, pp. 112-142. Springer, New York.

Uceda, Santiago

2013 Los de arriba y los de abajo: Relaciones sociales, políticas y económicas entre el templo y los habitantes en el núcleo urbano de las Huacas de Moche. En Investigaciones en la Huaca de la Luna 2004, editado por Santiago Uceda, Elias Mujica y Ricardo Morales, pp. 291-328. Facultad de Ciencias Sociales de la Universidad Nacional de Trujillo y Patronato Huacas del Valle de Moche, Trujillo, Perú.

van Andringa, William y Sébastien Lepetz

2003 Le ossa animali nei santuari: Per un'archeologia del sacrificio. En Les sources documentaires et leurs limites dans la description des lieux de culte: Actes de la table ronde organisée par le Collège de France, Naples, Centre Jean Bérard, 30 novembre 2001, editado por Olivier de Cazanove y John Scheid, pp. 85-96. Centre Jean Bérard, Nápoles.

Vega-Centeno, Rafael

2008 Consumo y ritual en la construcción de espacios públicos para el periodo Arcaico tardío: El caso de Cerro Lampay. En Boletín de Arqueología PUCP $n^{\circ} 9-2005$. Encuentros: Identidad, poder y manejo de espacios públicos, editado por Peter Kaulicke y Tom D. Dillehay, pp. 91-121. Pontificia Universidad Católica del Perú, Lima.

Velásquez Benites, Orlando

2001 Los muertos viven en el norte del Perú. En La Memoria de los ancestros, editado por Luis Millones y Wilfredo Kapsoli, pp. 153-189. Universidad Ricardo Palma, Editorial Universitaria, Lima.

Vigne, Jean-Denis y Marinval-Vigne Marie-Christine

1983 Méthode pour la mise en évidence de la consommation du petit gibier. En Animals and Archaeology 1: Hunters and their Prey, editado por Juliet CluttonBrock and Caroline Grigson, pp. 239-242. B.A.R. International Series 163. Archaeopress, Oxford.

Wing, Elizabeth. S.

1972 Utilization of Animal Resources in the Peruvian Andes. En Andes 4. Excavations at Kotosh, Peru, 1963 and 1966, editado por Seiichi Izumi et Kazuo Terada, pp 327-354. University of Tokyo Press, Tokyo.

1977 Caza y pastoreo tradicionales en los Andes peruanos. En Pastores de puna. Uywamichiq punarunakuna, editado por Jorge A. Flores Ochoa, pp 121-130. IEP, Lima.

Submitted April 13, 2017; Revised September 30, 2017; Accepted January 8, 2018 